\title{
陵水暗罗有效成分的研究一天然金屈 化合物暗罗素的分离及结构
}

韩公羽, 徐俩样 王肖鹏 刘明珠 许学余孟利宁 (第二军医大学)

陈仲良朱大元

(中国科学院上海约物研究所)

陵水暗罗 (Polyalthia nemoralis A. DC.) 为番荔枝科腤罗属植物 ${ }^{[1]}$, 产于广东南部和海南岛 地区. 海南民间用其根治疗疮疾和肝炎. 我们从 1972 年开始进行了其中抗症有效成分的分 离工作,从中分离出一种天然金属化合物，定名为暗罗素 (Zincpolyanemine), 得暴约十万分之 一,动物试验对疮疾有效.

暗罗素为黄色小方块结晶 (乙醇或丙酮结晶)或无绝针状结晶(氯仿结朚), 熔点 257 9 9 C. 紫外光谱 $\lambda_{\max }^{\mathrm{EtOH}} 246 \mathrm{~nm}(\log \varepsilon 4.73), 274(4.30) 、 327(3.78)$. 显示为芳香族化合物，其峰形大致 与吡啶衍生物一致。

暗罗素元素分析除一般的碳、氢、氧外，尚含有氮和硫，灰化后进行发射光谱分析，证明主 量元素为锌.

暗罗素的高分辨质谱,分子离子峰精密质量为 315,9323 , 计算分子式为 $\mathrm{C}_{10} \mathrm{H}_{3} \mathrm{~N}_{2} \mathrm{O}_{2} \mathrm{~S} 2 \mathrm{Zn}$, 与 元素分析结果相符. 其质谱并有明具的 $M+2$ 和 $M+4$ 同位素峰,各别的精密质量及丰度均 与理化值一致 (天然锌中存在多种同位素, 其中主要为 ${ }_{30} \mathrm{Zn}^{64} 、{ }_{30} \mathrm{Zn}^{66}$ 和 ${ }_{30} \mathrm{Zn}^{68}$ ). 。

暗罗素的核磁共振谱仅于芳香质子区出现四组共振信号. 化学位移 $\delta$ 值、峰型与裂分常 数各别如下:

(1) 8.51 , 双重双峰、 $J_{0}=9 \mathrm{~Hz} 、 J_{m}=1.5 \mathrm{~Hz}$ 、为 $\mathrm{C}_{6}-\mathrm{H}$.

(2) 7.70 , 双重双峰、 $J_{0}=9 \mathrm{~Hz} 、 J_{m}=1.5 \mathrm{~Hz}$ 、为 $\mathrm{C}_{3}-\mathrm{H}$.

(3) 7.35 , 双重三重峰, $J_{0}=9 \mathrm{~Hz} 、 J_{m}=1.5 \mathrm{~Hz}$ 、为 $\mathrm{C}_{5}-\mathrm{H}$.

(4) 7.09 , 双重三重峰, $J_{0}=9 \mathrm{~Hz} 、 J_{m}=1.5 \mathrm{~Hz}$ 、为 $\mathrm{C}_{4}-\mathrm{H}$.

由于暗罗素分子中共 8 个质子, 因此每组应各为二个化学等价的质子, 解析上述核磁信 号, 不难发现上述结果正与 2-取代吡啶一致.

暗罗素的红外光谱无厥基吸收, 具有芳香核吸收、1600、1550 $\mathrm{cm}^{-1}$, 芳香环四个邻接氢的 面外振动 $770 \mathrm{~cm}^{-1}$, 又于 $3410 \mathrm{~cm}^{-1}$ 出现一宽峰, 为氧化吡啶类化合物与 $\mathrm{H}_{2} \mathrm{O}$ 或醇类缔合班成 $\left.\left(\prod_{\mathrm{N}}^{\vdots}\right)_{\mathrm{O} \cdots \mathrm{H}-\mathrm{O}-\mathrm{R}}\right)$ 的吸收 ${ }^{[2]}, 1260 \mathrm{~cm}^{-1}$ 为

本文 1979 年 4 月 9 日收到.

第 6 期 
因而也证实 $\mathrm{N}$ - 氧化物结构的存在. 综上所述, 我们初步推定暗罗素的结构为

但其结合形式尚有多种可能.

我们从 2-氮基吡啶开始经五步人工合成了 2-放基吡啶- $\mathrm{N}$-氧化物锌盐, 其熔点为 257 $9^{\circ} \mathrm{C}$. 红外光谱与核磁共振谱也与天然品完全一致. 因而证明暗罗素的结构为:

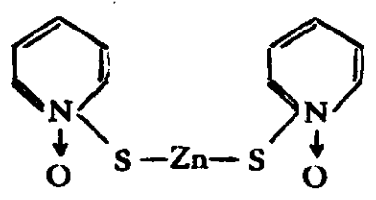

此化合物国外已经人工合成，并在美国、英国、日本均有专利报告 ${ }^{[3,4]}$ ，用作防每、杀菌剂， 而在植物中发现尚属首次, 而且这种金属化合物存在于高等植物中, 对植物生理、生化必然有 其重要意义.

\section{今 考文神}

[1] 中国科学院华南植物研究所编,海南植物志,第一卷, 247 .

[2] Koji Nakanishe, IR Absorption Spectroscopy, 1962, 55.

[ 3 ] Karsten, K. S. \& Taylor, W. S., V. S. Pat., 336,733, 1966; Judge, I. F. \& Kooyman, D. J., U. S. Pat., 381,366, 1966.

[4]森永京、昌谷忠、古谷算，日本公开特许,51-67718,1976。 